\title{
Fat and MEAT. A rare benign lesion of adipose tissue
}

\author{
Uwe Wollina ${ }^{1}$ 品
}

\begin{abstract}
The concept of mobile tumors was introduced by Shelley and Shelley in 2006. They coined the term abacus tumor. Mobile lipomas have been described in the literature as an example of abacus tumors. This was later questioned by Burgdorf et al., who performed comparative studies in cattle. They suggested the term mobile encapsulated adipose tissue (MEAT) for lipoma-like mobile lesions in cattle and people. We report two more cases of MEAT in adult patients and discuss the literature on this unusual subject.
\end{abstract}

Keywords: abacus tumor, mobile lipoma, mobile encapsulated adipose tissue, adipocytes

Received: 30 September 2017 | Returned for modification: 8 November 2017 | Accepted: 19 November 2017

\section{Introduction}

Human tumors are sessile. They grow at the site of their original development. Migration of tumor cells leads to satellites and metastases. A mobile tumor is unique. Shelley and Shelley (2006) coined the term abacus tumor to describe a marble-like subcutaneous mass that is freely mobile (1).

In the medical literature, several other terms can be found, such as nodular cystic fat necrosis (2), encapsulated fat necrosis (3), mobile encapsulated lipoma, (4) and mobile encapsulated adipose tissue (MEAT) (5).

The majority of reported cases are asymptomatic. There may be single or multiple lesions in one individual, and their size can vary considerably (6). Up to 100 MEAT lesions have been found in a single patient (7). MEAT occurs from childhood to advanced age. The lesions have been described in human subcutaneous tissue and occasionally in the peritoneum $(1-3,8,9)$.

In cows, peritoneal loose bodies, which are analogous to MEAT in humans, are not uncommon $(5,10)$. In a study by Herzog et al. (2010), all of the intraperitoneal lesions were described as firm, mobile, ivory-colored nodules with a distinct capsule ranging in size from 8 to $80 \mathrm{~mm}$. Their size is in the common range of human MEAT. They could be manually removed from the abdominal cavity without bleeding (10). These findings argue for nutrition of MEAT by diffusion because the lesions lacked a direct vascular support.

The peritoneal loose bodies of cows and the MEAT of humans have a similar gross morphology and histopathology. They are firm with a yellow cut surface and a surrounding capsule of variable thickness. The adipose tissue can show variably degenerated and necrotic adipocytes with lipo-membranous changes and may occasionally be calcified or fibrotic $(5,10)$.

Because cows have many epiploic appendices, these appendices could be the source for loose bodies (10). A similar development has been postulated for human peritoneal MEAT originating from infarcted epiploic appendages resulting in a free-floating lesion (8).

\section{Case report}

Case 1: a 57-year-old male patient presented to our department with a $3 \mathrm{~cm}$ subcutaneous mobile nodule on his lateral right brow.
No trauma was reported. A cystic tumor was suggested and the lesion was removed by surgical excision. The defect was sutured (Fig. 1). Healing was unremarkable. Histologic evaluation disclosed a tumor composed of mature adipocytes but covered by a fibrous capsule. The diagnosis of MEAT was confirmed.

Case 2: a 52-year-old female patient was referred to our department for a slowly growing tumor mass on her right flank after blunt trauma 3 years earlier. The lesion was mobile within a few centimeters. Surgery was performed to remove a tumor $6 \mathrm{~cm}$ in diameter, which had a marble-like surface. The defect was closed by a tissue advancement flap and sutured (Fig. 2). Healing was unremarkable. During follow-up of 2.5 years, no relapse occurred. Histological examination showed a larger tumor composed of adipocytes; there were no inflammatory lesions, but a fibrous capsule formation was noted. The diagnosis of MEAT was confirmed.

\section{Discussion}

In humans, traumas are often reported for subcutaneous MEAT. This explains why most subcutaneous MEAT lesions are located on the extremities $(2,7,11,12)$. The development of MEAT has also been described after Morel-Lavallée (ML) lesions, which occur when subcutaneous tissue is stripped from fascia and replaced with hematoma or necrotic fat (13).

Another possible pathogenetic factor is rapid vascular insufficiency because not all of the reported cases had a trauma history. Vascular insufficiency could be the reason for MEAT in connective tissue disease-such as scleroderma, lupus, dermatomyositis, or Ehlers-Danlos syndrome-or vasculitis and vasculopathy (14-20).

Most MEAT occur on the limbs because they are more prone to traumatic injury than the trunk. Their size is variable, although most MEAT are less than $3 \mathrm{~cm}$ in diameter. In contrast to this, loose bodies in cows can reach a considerably larger size than intraabdominal MEAT in humans do $(4,5,8,10)$. We noted two lesions of less common sites (i.e., the head and trunk), $3 \mathrm{~cm}$ and $6 \mathrm{~cm}$ in size, respectively. Smaller lesions have been described that could be moved up to $30 \mathrm{~cm}$. In our two cases, perhaps because of site and size, they were mobile up to $5 \mathrm{~cm}$ only.

The preferred treatment is surgical, and for subcutaneous lesions a simple excision is sufficient (3). The lesion must be distinguished histologically from other tumors and "pseudotumors" such as lipoma, angiolipoma, angioleiomyoma, angiomyoma, liposarcoma, 
alpha 1-antitrypsin deficiency-associated panniculitis, membranocystic, and pancreatic fat necrosis $(6,8,21)$.

In conclusion, MEAT is not a tumor and therefore the term abacus tumor is a misnomer. MEAT should be distinguished from lipoma because MEAT is the result of separation of fat with secondary changes and not the result of adipocyte proliferation (5). At the cellular level, MEAT shows "ghost cells" of preserved adipocytes without a nucleus closest to the fibrous capsule not seen in lipo- ma. Saponization, foamy histiocytes, and inflammatory infiltrates characteristic of pancreatic fat necrosis are completely missing in MEAT (6). Membranocystic fat necrosis (or membraneous lipodystrophy) is non-capsulated and has multiple cysts, and their membranes are reactive with period acid-Schiff reagent (PAS) (22). A mobile solid tumor has yet not been detected.

In memoriam Professor Walter Burgdorf (1943-2015).

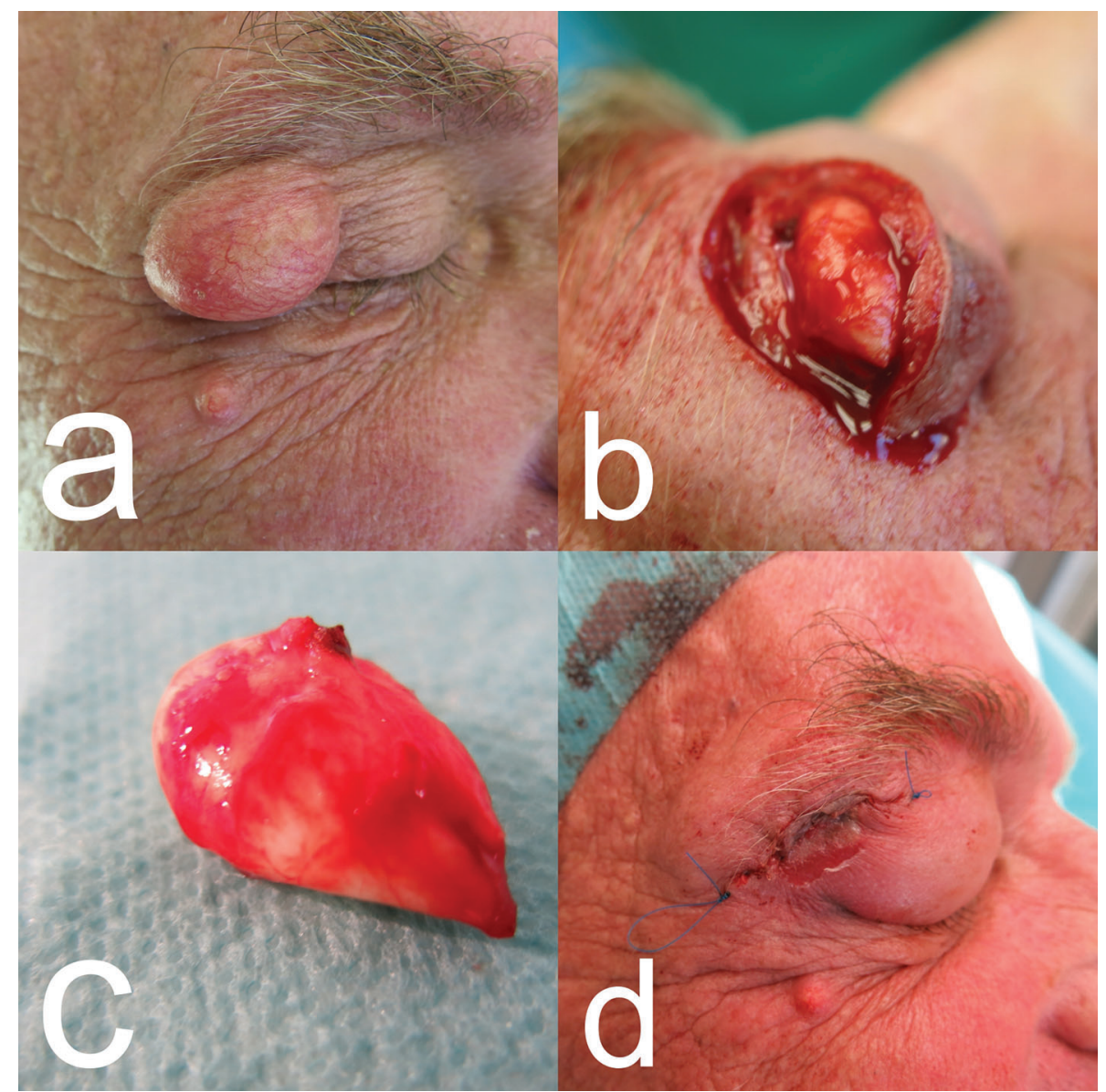

Figure 1 | Mobile encapsulated adipose tissue (MEAT) of the upper lid. (a) Clinical presentation of a mobile subcutaneous nodule. (b) Surgical site showing an encapsulated lesion unattached to the surrounding tissue. (c) MEAT after surgical removal. (d) Wound closure by tissue advancement flap.

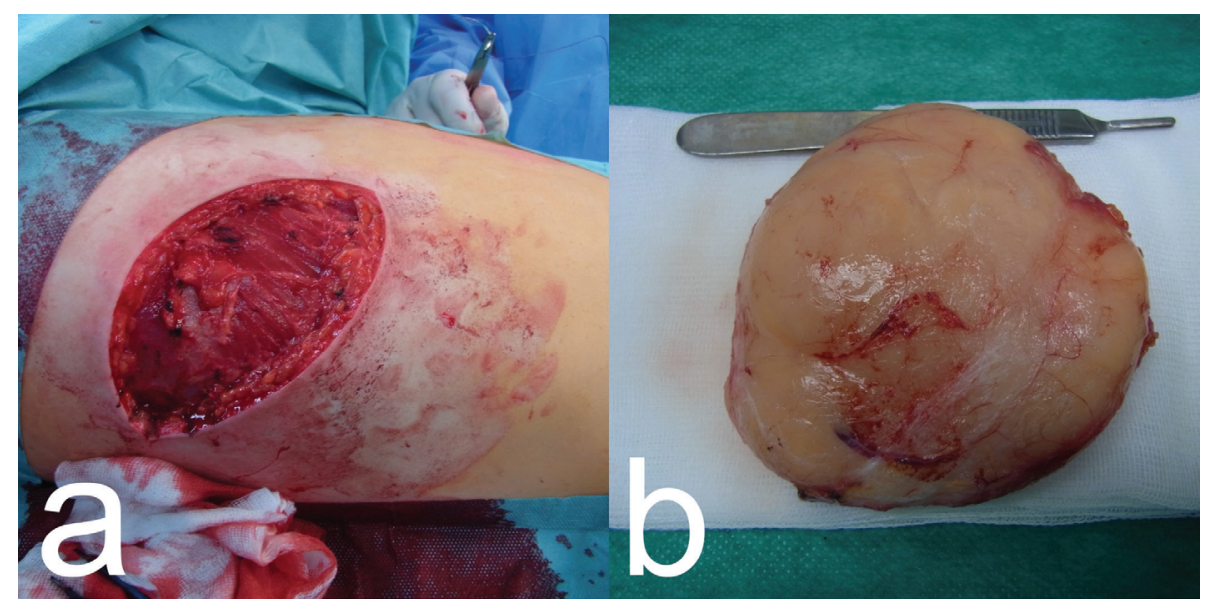

Figure 2 | Mobile encapsulated adipose tissue (MEAT) in the second patient. (a) Surgical site with the defect on the flank presenting the skeletal musculature. (b) Marble-like encapsulated large tumor; in the central portion the lesion was cut superficially to demonstrate the strong capsule formation typical for MEAT. 


\section{References}

1. Shelley WB, Shelley ED. Consultations in dermatology: studies of orphan and unique patients. New York: Cambridge University Press; 2006.

2. Przyjemski CJ, Schuster SR. Nodular-cystic fat necrosis. J Pediatr. 1977;91:6057.

3. Kiryu H, Rikihisa W, Furue M. Encapsulated fat necrosis-a clinicopathological study of 8 cases and a literature review. J Cutan Pathol. 2000;27:19-23.

4. Sahl WJ Jr. Mobile encapsulated lipomas. Formerly called encapsulated angiolipomas. Arch Dermatol. 1978;114:1684-6.

5. Burgdorf WHC, Hurt MA. Mobile encapsulated adipose tissue (MEAT) of cows and humans: a distinct nonneoplastic entity. Int J Surg Pathol. 2011;19:576-82.

6. Hurt MA, Santa Cruz DJ. Nodular-cystic fat necrosis. A reevaluation of the socalled mobile encapsulated lipoma. J Am Acad Dermatol. 1989;21:493-8.

7. Tukenmez Demirci G, Mansur AT, Ozker E, Demiralay E. An extraordinary manifestation of nodular cystic fat necrosis. Am J Dermatopathol. 2016;38:e33-5.

8. Oh HB, Arab N, Teo L, Lieske B. Snapshot in surgery: intraperitoneal encapsulated fat necrosis. Clin Case Rep. 2015;3:131-2.

9. Magalhães R, Oliveira J, Caridade S. Citoesteatonecrose abdominal encapsulada. Acta Med Port. 2016;29:673.

10. Herzog K, Burgdorf W, Hewicker-Trautwein M. Mobile encapsulated bodies comprising fat necrosis and fibrous tissue in the abdominal cavity of cows. J Comp Path. 2010;143:309-12.

11. Yi-Hsin H, Ya-Wen H, Yi-Chin S. Multiple floating fat balls on the right lower leg. Nodular cystic fat necrosis. Indian J Dermatol Venereol Leprol. 2011;77:731-2.

12. Sole JS, Wisniewski SJ, Dahm DL, Bond J, Smith J. Posttraumatic fat necrosis presenting as prepatellar loose bodies in an adolescent football player. PM R. 2014;6:749-52.
13. Vopat BG, Wong JE, Hazzard S, Golijanin P, Palmar WE, Asnis PD. Encapsulated fat necrosis lesion caused by Morel-Lavallée lesion in a professional ice hockey player. Am J Orthop (Belle Mead NJ). 2017;46:E144-7.

14. Toritsugi M, Yamamoto T, Nishioka K. Nodular cystic fat necrosis with systemic sclerosis. Eur J Dermatol. 2004;14:353-5.

15. Ferenczi K, Berke A, Makkar HS. Nodular cystic fat necrosis with calcification in a patient with juvenile dermatomyositis. Pediatr Dermatol. 2014;31:588-90.

16. Demitsu T, Yoneda K, lida E, Takada M, Hiratsuka Y, Azuma R, et al. A case of nodular cystic fat necrosis with systemic lupus erythematosus presenting the multiple subcutaneous nodules on the extremities. J Eur Acad Dermatol Venereol. 2008;22:885-6.

17. Ohtke N, Gushi A, Matsushita S, Kanzaki T. Encapsulated fat necrosis in a patient with Ehlers-Danlos syndrome. J Cutan Pathol. 1997;24:189-92.

18. Ahn SK, Lee BJ, Lee SH, Lee WS. Nodular cystic fat necrosis in a patient with erythema nodosum. Clin Exp Dermatol. 1995;20:263-5.

19. Ueda N, Satoh T, Yamamoto T, Yokozeki H. Nodular cystic fat necrosis in Heerfordt's syndrome. J Eur Acad Dermatol Venereol. 2007;21:708-9.

20. Kubota Y, Nakai K, Moriue T, Yokoi I, Fujita N, Miyamoto I, et al. Nodular cystic fat necrosis in a patient with diabetes mellitus. J Dermatol. 2009;36:353-4.

21. Lee SA, Chung HW, Cho KJ, Sung CK, Lee SH, Lee MH, et al. Encapsulated fat necrosis mimicking subcutaneous liposarcoma: radiologic findings on MR, PET-CT, and US imaging. Skeletal Radiol. 2013;42:1465-70.

22. Akpinar F, Demir E, Apa DD. Membranous lipodystrophy: case report and review of the literature. An Bras Dermatol. 2015;90:115-7. 